been moved is an expression of an amount of light transmitted by the paper to the velvet and then $a b-$ sorbed. This scale reading furnishes a basis for expressing the translucent effect of paper since this effect is dependent upon the light transmitted.

The essential construction of the instrument is shown in the photograph. It must be used in a darkened room and for illumination a frosted roo-watt stereopticon bulb (Mazda) is preferable, as it gives a centralized light. One of materially more watts is too brilliant for accurate work.

The character of results obtained is shown in Table $I$, in which the papers are arranged in the order of translucent effect to the naked eye, and the original and check scale readings and the percentages of translucent effects are recorded.

\begin{tabular}{|c|c|c|c|}
\hline \multicolumn{4}{|c|}{ TABLE I-一RESUITS OBTAINED } \\
\hline $\begin{array}{l}\text { Arranged by } \\
\text { Naked Eye }\end{array}$ & $\begin{array}{c}\text { 1st } 5 \text { Readings } \\
\text { Mm. }\end{array}$ & $\begin{array}{c}\text { 2nd } 5 \text { Readings } \\
\mathrm{Mm} .\end{array}$ & $\begin{array}{c}100\left(1-b^{2} / a^{2}\right) \\
\text { Per cent }\end{array}$ \\
\hline 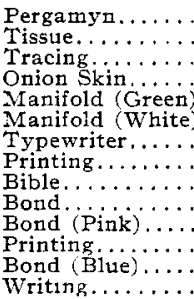 & 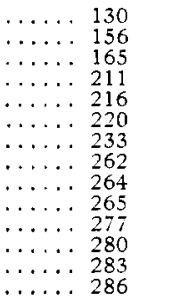 & $\begin{array}{l}129 \\
155 \\
165 \\
213 \\
218 \\
222 \\
235 \\
265 \\
265 \\
265 \\
277 \\
278 \\
283 \\
288\end{array}$ & $\begin{array}{l}81.4 \\
73.1 \\
69.7 \\
50.1 \\
47.7 \\
45.7 \\
39.1 \\
22.8 \\
22.3 \\
22.0 \\
14.7 \\
13.5 \\
11.0 \\
9.5\end{array}$ \\
\hline
\end{tabular}

It is difficult for the naked eye to distinguish between green manifold and white manifold, and also between pink bond and printing. The instrument, however, places them with greater certainty. The order by the naked eye was confirmed by three independent observers.

The backgrounds of magnesium carbonate blocks give very satisfactory smooth, clean, reproducible white surfaces. Only a small area of paper should be exposed since it can be more readily held in close contact with the surface of the block or the black velvet, thus aiding greatly the sensitiveness of the instrument. The blocks must move freely on the tracks for ease of manipulation and accuracy.

Since the intensity of light varies inversely as the square of the distance from the luminous point, the reading, on any paper, substituted in the formula IoO( $\left.I-\frac{b_{2}}{a_{2}}\right)$ gives a value for comparison of the approximate percentage loss of light due to absorption by the black velvet. In the formula, $a$ is the total scale reading and $b$ is the distance that the block is removed from zero.

The prisms of the eyepiece are cut at $4 \Sigma^{\circ}$ angles to reflect adjacent fields and the eyepiece is long to permit the comparisons to be made with the least fatigue. A collar of metal or cardboard may be placed on the eyepiece to shade the eyes from the light of the bulb. A strip may be similarly placed across the track directly over the bulb, or, the instrument may be constructed with the eyepiece horizontal.

In the measurement of the translucent effect of the paper an exact match of color cannot be realized as there is a difference due to the absorption of light by the black velvet. This difficulty is overcome by making the comparisons through a colored glass, either green or brown, placed on the eyepiece.

A colored paper should always be matched through a glass of its predominating hue.

When experience is gained in judging the luminosity match, rather than the color, the method and instrument give results which are satisfactory for all industrial purposes. The instrument should prove practical because of its sensitiveness, low cost, and ease of manipulation over other instruments.

Crane \& COMPANY

Dalton, Mass.

\section{A PRACTICAL REVISION OF THE COBALTI-NITRITE METHOD FOR THE DETERMINATION OF POTASH}

BY R. C. HAFF ${ }^{1}$ AND E. H. SCHWARTZ 1 Recejved July 9. 1917

Some years ago, there appeared in THIS JoLRAAL2 the method for the determination of potash by the use of cobalti-nitrite.

About a year ago, when the Security Cement \& Lime Company began actual operations with their new treater plant with the idea of collecting and selling the dust on account of its high content of water-soluble potash, we were called upon to make a very large number of determinations for potash, not oniy on our own materials but on many other cement and foreign. materials as well.

Since many of these determinations, on which total potash was also required, were made along research lines, mainly, the more laborious and very tedious J. Lawrence Smith method, while it proved very satisfactory as to accuracy of results, was found to be quite impracticable, due to the large laboratory force required and the time consumed in getting our final results.

Tpon receipt of information that the cobalti-nitrite method was employed in the laboratories of the Western Precipitation Company, at Los Angeles, Cal., and in those of Mr. Charles Catlett, at Staunton, Va, we decided to attempt to employ it at Security with the idea of perfecting it in a more uniform laboratory routine, providing we could rely upon the results to check satisfactorily those obtained when employing the recognized Official methods.

The early work with this method required a very great number of duplicate determinations on all grades of material, and particular stress was laid upon the accuracy and reliability of "total potash" results, since all duplicate results on raw material and clinker, in particular, had to be accurate within 0.02 per cent $\mathrm{K}_{2} \mathrm{O}$.

This method has been employed in our laboratory at Security for about nine months and has been found to give most satisfactory results on "total potash" when checked against the J. Lawrence Smith method and on "water-soluble potash" when checked against the Official methods employed and recommended by the American Official Agricultural Chemists.

1 Chief Chemist and Assistant Chemist, respectively, for the Security Cement and Lime Co., Hagerstown. Md.

2 This Journal, 1 (1909), T91. 


\section{METHOD IN DETAIL}

I-Weigh out a 2 gram sample of raw material (or clinker) or a 0.5 gram sample of treater dust and add to the former $0.5 \mathrm{~g}$. of ammonium chloride and to the latter $0.25 \mathrm{~g}$. of ammonium chloride. Transfer to a mortar, mix thoroughly and grind. Transfer the contents of the mortar to a $20 \mathrm{cc}$. platinum crucible, the bottom of which has been covered with a generous layer of calcium carbonate-about 2 grams. Cover contents of crucible with about 2 grams of calcium carbonate and proceed with heating and sintering as in the J. Lawrence Smith method.

After the mass has been slaked in a small casserole, place on the hot plate and heat to boiling. Filter into a flat-bottomed porcelain dish and wash the precipitate 3 or 4 times with very hot water. Add to the filtrate an excess of acetic acid ( 5 to ro cc.) and evaporate on a steam bath until no odor of acetic acid remains. Take up with a little hot water, using the precaution to wash the sides of the dish thoroughly. Now add from to to $\mathrm{I} 5 \mathrm{cc}$. of cobalt reagent (see below) and evaporate on steam bath to pasty consistency. Remove from bath and when precipitate has cooled, take up with about $30 \mathrm{cc}$. of cold water, breaking up precipitate thoroughly.

Filter through an asbestos padded Gooch crucible and wash precipitate once with cold water. ${ }^{1}$

Wash contents of crucible into a $400 \mathrm{cc}$. beaker (containing an excess of standard $N / 5$ potassium permanganate solution) ${ }^{2}$ with hot water ard dilute to $25^{\circ}$ cc.

Place on steam bath for about I 5 minutes or until a decided black color appears. Acidulate with ro cc. I : I sulfuric acid. With a standard pipette (Io cc.) neutralize the excess potassium permanganate with $N / 5$ oxalic acid solution, the potassium permanganate equivalent of which has been determined. When the final solution has cleared, titrate with standard potassium permanganate solution.

COBALT-NitRITE SOLUTION-(I) Dissolve $220 \mathrm{~g}$. of sodium nitrite in $400 \mathrm{cc}$. of water.

(2) Dissolve II $3 \mathrm{~g}$. of cobalt acetate in a mixture of $300 \mathrm{cc}$. of water and $100 \mathrm{cc}$. of glacial acetic acid.

(3) Mix the above solutions and place under vacuum over night. Filter and dilute to rooo cc. Keep the solution in a dark bottle. Never use a solution over two weeks old.

II-When determining "water-soluble" potash by this method, weigh $10 \mathrm{~g}$. of the material into a $600 \mathrm{cc}$. beaker, cover with about $250 \mathrm{cc}$. of water and boil for 30 minutes. Pour into a $500 \mathrm{cc}$. flask. Cool to room temperature. Make solution to mark. After shaking well, filter a portion of the solution through a dry paper. Draw off $50 \mathrm{cc}$. (I gram equivalent) and place in a platinum or porcelain dish. Then proceed as in the above method, beginning with "Add to the filtrate an excess of acetic acid ( 5 to io cc.) and evaporate on steam bath until no odor of acetic acid remains."

1 Water poured from a beaker causes less disturbance in the crucible and gives better results.

$210 \mathrm{cc}$. for each 1 per cent $\mathrm{K}_{2} \mathrm{O}$ equivalent in the sample.
ILIUSTRATION-RESULTS ON SAMPLE OF RAW MATERIAL DATA-2O cc. Permanganate originally used; Io cc. Oxalic acid used to neutralize excess Permanganate; Io cc. Oxalic acid found to equal if $.2 \mathrm{cc}$. Permanganate; 5 cc. Permanganate used to neutralize excess Oxalic acid. Now $(20 \mathrm{cc} .+5 \mathrm{cc}$.) - I I.2 cc. (Oxalic acid equivalent) $=$ No. of cc. of Permanganate used to complete titration. Therefore (No. of cc. of Permanganate) $\times$ Factor $=$ per cent $\mathrm{K}_{2} \mathrm{O}$.

$$
\text { CALCULATION OF } \mathrm{K}_{2} \mathrm{O} \text { FACTOR- }
$$

$\frac{\mathrm{CaO} \text { Factor }}{2}: 0.0056=X: 0.0017 \mathrm{I}$, where $X=\mathrm{K}_{2} \mathrm{O}$ factor.

Regular $N / 5$ Permanganate is used where the calcium oxide factor is based on 0.5 gram. To calculate the $\mathrm{K}_{2} \mathrm{O}$ factor to I gram, one-half of the calcium oxide factor must be used in the above proportion.

Security Cemment \& Lime Company Hagerstown, Maryland

\section{DETERMINATION OF CARBONATES IN LIMESTONE AND OTHER MATERIALS}

By J. F. BAREER

Received May 18, 1917

Results obtained in the determination of carbonates by the apparatus herein described compare favorably with results from the use of any standard laboratory method. The advantage of this method over others is that no mechanical balance or scale is required and there are no long calculations to be made. Anyone with some aptitude for accuracy can, with this instrument, make as reliable a determination in home or office as a skilled chemist in a well-equipped laboratory using complicated apparatus.

The invention depends upon the principle of the hydrometer, which takes account of the law that when an object is immersed in a liquid it is buoyed up by a force equal to the weight of the liquid displaced by the object. In this apparatus the carbon dioxide gas set free from the sample decreases the weight; and the rise of the graduation scale tube above the water records the percentage of carbonates from which the gas was released.

\section{PROCEDURE}

To analyze a sample of limestone for carbonates, measure out $40 \mathrm{cc}$. of $\mathrm{HCl}$ (sp. gr. I. I5), using a small graduate; pour this into the acid reservoir through the opening $A$. With graduated stem disconnected hang a Io-g. weight at $B$. The hydrometer should then float in a cylinder of water and be immersed to some point at $C$. Remove the ro-g. weight and introduce pulverized limestone until instrument is immersed to exactly the same point. Now connect up graduated stem and add water a drop at a time, through the funnel-shaped top, until immersed to zero point. Raise hydrometer out of water and open stopcock $D$ until acid drops slowly into reaction chamber, decomposing the limestone. As the reaction proceeds the instrument rises slowly and at the conclusion the point on stem at the surface of the water gives the per cent of calcium carbonate equivalent to the carbon dioxide in the sample. This figure is the calcium carbonate equivalent so often mentioned in connection with limestone analyses. 